\title{
Long-term outcomes of stenting and endarterectomy for symptomatic carotid stenosis: a pre-planned pooled analysis of individual patient data
}

\author{
Prof Thomas G Brott, MD ${ }^{\star}, 1$, David Calvet, MD ${ }^{\star}, 2$, Prof George Howard, DrPH ${ }^{3}$, John \\ Gregson, $\mathrm{PhD}^{4}$, Prof Ale Algra, MD ${ }^{5}$, Prof Jean-Pierre Becquemin, MD ${ }^{6}$, Prof Gert J. de \\ Borst, MD7, Richard Bulbulia, MD ${ }^{8,9}$, Prof Hans-Henning Eckstein, MD ${ }^{10}$, Prof Gustav \\ Fraedrich, $\mathbf{M D}^{11}$, Jacoba Greving, $\mathbf{P h D}^{12}$, Prof Alison Halliday, $\mathbf{M S}^{8,9}$, Prof Jeroen \\ Hendrikse, MD ${ }^{13}$, Prof Olav Jansen, PhD ${ }^{14}$, Jenifer H Voeks, PhD ${ }^{15}$, Peter A Ringleb, PhD ${ }^{\star *}$, \\ ${ }^{16}$, Prof Jean-Louis Mas, MD ${ }^{\star *}, 17$, Prof Martin M Brown, FRCP ${ }^{\star \star}, 18$, Prof Leo H Bonati, MD ${ }^{\star \star}$, \\ 18,19 on behalf of the Carotid Stenosis Trialists' Collaboration
}

${ }^{1}$ Department of Neurology, Mayo Clinic, Jacksonville, FL ²Department of Neurology, Hôpital Sainte-Anne, Université Paris-Descartes, DHU Neurovasc Sorbonne Paris Cité, INSERM U894, Paris, France ${ }^{3}$ Department of Biostatistics, UAB School of Public Health, Birmingham, AL ${ }^{4}$ Department of Medical Statistics, London School of Hygiene and Tropical Medicine, London, UK ${ }^{5}$ Department of Neurology and Neurosurgery, Brain Center Rudolf Magnus and Julius Center for Health Sciences and Primary Care, University Medical Center Utrecht and Utrecht University Utrecht, the Netherlands ${ }^{6}$ Vascular Institute of Paris East, Hôspital Paul D Egine, Champigny-surMarne, 94500 France ${ }^{7}$ Department of Vascular Surgery, University Medical Center Utrecht, Utrecht University, Utrecht, the Netherlands ${ }^{8}$ Clinical Trial Service Unit and Epidemiological Studies Unit (CTSU), Nuffield Department of Population Health, University of Oxford, UK ${ }^{9} \mathrm{MRC}$ Population Health Research Unit, Nuffield Department of Population Health, University of Oxford, UK ${ }^{10}$ Department of Vascular and Endovascular Surgery/Vascular Center, Klinikum rechts der Isar der Technischen Universität München, Munich, Germany ${ }^{11}$ Department of Vascular Surgery, Medical University of Innsbruck, Austria ${ }^{12}$ Julius Centre for Health Sciences and Primary Care,

Corresponding author: Martin M Brown MD FRCP, Professor of Stroke Medicine, Stroke Research Centre, UCL Queen Square Institute of Neurology, Box 6, The National Hospital for Neurology \& Neurosurgery, Queen Square, London WC1N 3BG, UK, Tel: +44333888 8888, martin.brown@ucl.ac.uk.

Contributed equally

Contributed equally

\section{Authors Contributions}

Thomas G Brott and David Calvet wrote the first drafts of the paper. George Howard and John Gregson undertook the statistical analysis. Jean-Louis Mas, Peter Ringleb, Leo Bonati, and Jenifer Volks extracted individual patient data from the contributing trials. All authors made substantial contributions to the conception and design of the study, acquisition of data or analysis, data interpretation and critical revision of the article. Thomas Brott and Martin Brown had the final responsibility for the analyses and manuscript content.

Declarations of Interest

TB reports grants from National Institutes of Health, during the conduct of the study. LHB reports grants from Swiss National Science Foundation, grants from University of Basel, during the conduct of the study; grants from Swiss National Science Foundation, grants from Swiss Heart Foundation, grants and non-financial support from AstraZeneca, personal fees from Amgen, personal fees and nonfinancial support from Bayer, personal fees from Bristol-Myers Squibb, personal fees from Claret Medical, outside the submitted work. PR reports grants from BMBF/DFG for funding of the SPACE-Study during the conduct of the study. JG reports personal fees from Edwards Lifesciences, outside the submitted work. JV reports grants from NIH, during the conduct of the study. 
University Medical Centre Utrecht, Utrecht, the Netherlands ${ }^{13}$ Department of Radiology, University Medical Center Utrecht, Utrecht, the Netherlands ${ }^{14}$ Clinic for Radiology and Neuroradiology, UKSH Campus Kiel, Kiel, Germany ${ }^{15}$ MUSC Stroke Center, Medical University of South Carolina, Charleston, SC ${ }^{16}$ Department of Neurology, University of Heidelberg Medical School, Heidelberg, Germany ${ }^{17}$ Department of Neurology, Hôpital Sainte-Anne, Université ParisDescartes, DHU Neurovasc Sorbonne Paris Cité, INSERM U894, Paris, France ${ }^{18}$ Stroke Research Centre, Department of Brain Repair and Rehabilitation, UCL Queen Square Institute of Neurology, University College London, London, UK ${ }^{19}$ Department of Neurology and Stroke Center, University Hospital Basel, Basel, Switzerland

\section{Abstract}

Background-The risk of peri-procedural stroke or death is higher following carotid artery stenting (CAS) than carotid endarterectomy (CEA) for the treatment of symptomatic carotid stenosis. However, long-term outcomes have not been sufficiently assessed. We sought to combine individual patient-level data from the four major randomised controlled trials of CAS versus CEA for the treatment of symptomatic carotid stenosis to assess long-term outcomes.

Methods-Individual patient-level data was acquired from EVA3S, SPACE, ICSS, and CREST, the four largest randomised controlled trials assessing the relative efficacy of CAS and CEA for treatment of symptomatic carotid stenosis. We did a pooled analysis to assess the risk of ipsilateral stroke between 121 days and 1, 3, 5, 7, 9, and 10 years after randomisation, as well as the composite risk of stroke or death within 120 days after randomisation, or subsequent ipsilateral stroke up to 10 years after randomisation. Analyses were intention-to-treat, with the risk of events calculated using Kaplan-Meier methods, and Cox proportional hazards analysis with adjustment for trial.

Findings-Of 4775 patients randomised, a total of 4754 patients were followed up for a maximum of 12.4 years; 21 patients who immediately withdrew consent after randomization were excluded. Median length of follow-up across the studies ranged from 2.0 to 6.9 years. There were 129 peri-procedural and 55 post-procedural outcome events among those allocated CEA, and 206 and 57 for those allocated CAS. The long-term outcomes after the peri-procedural period, the annual rates of ipsilateral stroke per person year, were similar for the two treatments, $0.60 \%$ (95\% CI: 0.46 to 0.79 ) for CEA and $0.64 \%$ (95\% CI: 0.49 to 0.83 ) for CAS. Nonetheless, the peri- and post-procedural risks combined favoured CEA, with treatment differences at 1, 3, 5, 7 and 9 years all ranging between $2.8 \%$ (95\% CI: $1.1 \%$ to $4.4 \%$ ) and $4.1 \%$ (95\% CI: 2.0 to $6.3 \%$ ).

Interpretation-Long-term outcomes in the post-procedural period following CAS and CEA were similar, suggesting robust clinical durability for both treatments. Although long-term outcomes (per-procedural and post-procedural risk combined) continue to favour CEA, the similarity of the post-procedural rates suggest that improvements in the peri-procedural safety of CAS could provide similar outcomes of the two procedures in the future.

Funding-There was no funding supporting this analysis. 


\section{Introduction}

Randomized controlled trials of patients with recently symptomatic carotid stenosis have compared treatment with carotid artery stenting (CAS) with carotid endarterectomy (CEA) (1-5). Over a relatively short time horizon of two to three years following the procedures, individual studies have shown higher risk for the composite of peri-procedural stroke and death and subsequent ipsilateral stroke following CAS compared with CEA. Because life expectancies for men and women of ages similar to those in these trials exceed 10-15 years, differences in the occurrence of stroke beyond two to three years are clinically meaningful (6).

The imprecision of the long-term data from individual studies fails to provide clinicians and patients with the information they need to make treatment decisions and to adjudge longterm prognosis. The number of patients followed for more than 5 years in individual trials was limited, 363 patients in the Endarterectomy versus Angioplasty in Patients with Symptomatic Severe Carotid Stenosis (EVA-3S) to this point, 596 from the International Carotid Study (ICSS), and 700 symptomatic patients from Carotid Revascularization Endarterectomy vs. Stenting Trial (CREST). There were no patients from the StentProtected Angioplasty versus Carotid Endarterectomy in symptomatic patients (SPACE) followed to 5 years. Accordingly, investigators representing the four major randomized trials - EVA-3S, SPACE, ICSS and CREST- have combined long-term outcome data of individual patients in a pooled analysis, which are reported in this paper. The primary outcome is the occurrence of ipsilateral stroke during the post-procedural period, beyond 120-days and out to 10-years. The peri- and post-procedural outcomes combined, the outcomes approximating the primary endpoints of the individual trials, are also analyzed. Although the analyses were pre-planned, there is no published protocol available.

\section{Methods}

\section{Trials}

EVA-3S, SPACE, ICSS, and CREST were multicentre, randomised trials that compared outcomes following CAS and CEA of patients with moderate or severe atherosclerotic symptomatic stenosis at the carotid bifurcation(7). The Carotid Stenosis Trialists' Collaboration requested, received and harmonized the individual patient-level data for each of these trials. These data have served as the bases for a series of reports including the current analysis. CREST also enrolled patients with asymptomatic carotid stenosis who are not included in this analysis. Stenosis eligibility was $\geq 60 \%$ in EVA-3S, $\geq 50 \%$ in SPACE, > $50 \%$ in ICSS, and $\geq 70 \%$ in CREST, all by duplex ultrasound and corresponding to angiographic values obtained with methods used in prior trials (CREST also allowed enrolment of patients with $\geq 50 \%$ stenosis by catheter angiogram). Patients were randomised from November of 2000 through July of 2008. Enrolment in EVA-3S was halted in September of 2005 per recommendation of the safety committee.(1) Enrolment in SPACE was also stopped prematurely following an interim analysis, for reasons of futility and lack of funding.(2) Each of the trials contributing data were reviewed and approved by the appropriate ethics committees. 
Credentialing and device use varied for carotid stenting, the experimental procedure. In

EVA-3S, ICSS, and CREST interventionists had to have performed at least 12, 10, and 30 carotid-stenting procedures respectively, and additional criteria varied. In SPACE, interventionists had to have performed at least 25 successful consecutive angioplasty or stent procedures, not necessarily of the carotid artery. Choice of stenting devices was at the discretion of the interventionist in EVA-3S, SPACE, and ICSS. The use of approved cerebral protection devices was optional in SPACE and ICSS. Protection devices were made mandatory in EVA-3S after an interim analysis showed a higher risk of procedural stroke with unprotected stenting than with protected stenting (8). CREST required use of the ACCUNET $^{\circledR}$ protection device, Abbott, Temecula, CA, USA, and the ACCULINK $^{\circledR}$ stent, Abbott, Temecula, CA, USA.

\section{Outcome events}

The authors' pre-defined main long-term outcome analysed is ipsilateral stroke during the post-procedural period. Treatment differences at 1, 3, 5, 7, 9, and 10 years after randomization are reported. These points were chosen arbitrarily without consideration of the specific pattern of treatment differences. The pre-defined is the composite of stroke or death occurring within 120 days after randomisation, or subsequent ipsilateral stroke(5). In the original reports of the individual trials, the periprocedural period was 0-30 days after CEA or CAS in EVA-3S, 0-30 days after randomisation in SPACE and CREST, and 0-120 days after randomisation in ICSS. The cutpoint for the peri- and post-procedural periods at 120 days after randomisation was chosen for the analyses here because in each contributing trial nearly all patients received their treatment within 3 months of randomisation and received their post-treatment follow-up appointment within 4 months after randomisation. Accordingly, outcomes during this peri-procedural period of 0-120 days are also reported. In addition to examining treatment differences at the above fixed time points, the hazard ratio over the entire follow-up period extending to the end of follow-up was considered.

Secondary outcomes include major stroke, minor stroke, and stroke in any distribution; for brevity the treatment differences for these secondary outcomes are provided only for the 5year point in follow-up. Additionally, analysis was performed for ipsilateral and nonipsilateral stroke outcomes showing similar patterns to those reported herein, but these results are not reported in detail for reasons of brevity. Stroke was defined as an acute neurologic event with focal symptoms and signs, lasting for 24 hours or more, that were consistent with focal cerebral ischaemia; visual loss resulting from retinal ischaemia that lasted for longer than 24 hours, was included within the category of stroke. None of the 4 trials used a tissue-based definition of stroke, and therefore patients with symptoms less than 24 hours in duration with positive MRI scans were not classified as stroke. Major stroke was defined in EVA-3S, SPACE, and ICSS as any stroke resulting in a modified Rankin scale of 3 or greater, 30 days or more after stroke onset. In CREST, major stroke was defined on the basis of clinical data or if the NIHSS score was 9 or higher 90 days after the randomization. Patients were evaluated neurologically after the procedure, and had follow-up evaluations at 30-36 days, 6 months, and at least annually thereafter. Potential outcome events were adjudicated by independent committees. Medical treatments followed standard of care, and patients were continued to be followed for stroke events after any carotid revasularization procedure. 


\section{Data Analysis}

Analyses were intention-to-treat (ITT) and included all randomised patients, with the exception of 21 patients who immediately withdrew consent after randomization. For both the peri-procedural and post-procedural periods, the crude differences in the proportion of patients with events were assessed with Kaplan-Meier methods, and Cox proportional hazards analysis was used to estimate CAS-to-CEA hazard ratios (HRs) after adjustment for the contributing trial. For the ITT analysis, the periprocedural period was defined as the first 120 days after randomisation. All patients who had an event (stroke or death) or who withdrew from the studies during the periprocedural period were omitted from the postprocedural analysis, which started at 121 days after randomization. The potential for a heterogeneity of treatment effect between studies was assessed by the introduction of a treatment-by-study interaction term to the proportional hazards model. An additional perprotocol analysis was done, including only those patients in whom the first initiated revascularisation procedure after randomisation was the randomly allocated treatment. Patients crossing over to the alternative procedure, those remaining on medical treatment only, and patients who died before treatment were excluded from the per-protocol analysis. For the per-protocol analysis, the periprocedural period was defined as the first 30 days after revascularization, and the postprocedural period started at 31 days after revascularisation.

Subgroup analysis was performed where patients were stratified by covariates that potentially could affect CAS-CEA treatment differences, with treatment differences assessed for the entire follow-up (including both peri-procedural and post-procedural periods) and for the post-procedural period alone. Within each stratum, proportional hazards analysis was used to calculate the CAS-to-CEA hazard ratio after adjustment for the contributing trial, and the significance of potential treatment effect modification by the covariate was assessed by the addition of an interaction term to the proportional hazards model (statistical testing for interactions using an a priori $\mathrm{a}=0.10$ ).

\section{Role of funding source}

The funding agencies and companies that funded the original trials contributing to this analysis did not have access to the data, did not participate in the planning or funding of this analysis, and had no role in the preparation of this report.

\section{Results}

For the 4754 patients (Figure 1), maximum follow-up was 12.4 years in EVA-3S, 4.1 years in SPACE, 10.0 years in ICSS, and 10.2 years in CREST. Median follow-up ranged between 2.0 to 6.9 years (Table 1). About $30 \%$ of patients were females, three quarters had hypertension, and about $70 \%$ were dyslipidaemic. About a quarter were current smokers, and $15 \%$ had severe $(>=50-70 \%)$ contralateral carotid stenosis or occlusion (Table 1).

The previously estimated peri-procedural 120-day stroke or death CAS versus CEA treatment difference from the 3 European trials was 3.2\% (95\% CI: $1.4 \%$ to $4.9 \%$ ). (5) In this analysis that included data from the CREST trial, this estimate is unchanged (3.2\%), but 
with the increased sample size (now 4,754) tightening the 95\% confidence bounds to $1.7 \%$ to $4.7 \%$ (Table 2).

Beyond 120 days, the occurrence of stroke in the long-term was infrequent, and rates did not differ by CAS or CEA treatment at 5-years (Table 2), nor did the proportion of patients with events (Table 3). The absolute CAS versus CEA treatment difference in post-procedure stroke risk at years $1,3,5,7$ or 9 never exceeded $1 \%$, ranging from $-0.6 \%$ (95\% CI: $-1.6 \%$ to $0.4 \%$ ) at year 3 to $0.6 \%$ (95\% CI: $-0.7 \%$ to $2.0 \%$ ) at year 7 . Fifty-seven (57) ipsilateral strokes occurred in the CAS cohort, and 55 ipsilateral strokes occurred in the CEA cohort, CAS-to-CEA hazard ratio 1.06 (95\% CI, 0.73 to 1.54 ) (Table 2). The annual rate of postprocedural ipsilateral stroke per person year was similar for CEA $(0.60 ; 95 \% \mathrm{CI}: 0.46$ to 0.79 ) and CAS ( $0.64 ; 95 \%$ CI: 0.49 to 0.83$)$ (Table 2). The rates of major stroke and minor stroke were also less than $1 \%$ per year (Table 2). These results out to 5 years (Table 2) are consistent with the results out to 9 years (in Table 3) and the Kaplan-Meier curves (Figure 1 A-H).

With the similarity of post-procedure stroke for those assigned to CAS and CEA, the 3.2\% peri-procedural stroke risk was carried forward over the entire follow-up period, never differing from this initial treatment difference by more than $1 \%$ (Table 3, Figure 2B). Over the entire follow-up, the hazard for the primary event was 1.45-times (95\% CI: 1.20 to 1.75) higher for those assigned to CAS (Table 2, Figure 2A).

The post-procedure CAS versus CEA treatment differences were also quite small for major stroke (at 5-years: $-0.2 \%$ with $95 \% \mathrm{CI}-1.0 \%$ to $0.6 \%$; $\mathrm{HR}=0.86$ with $95 \% \mathrm{CI}: 0.48$ to 1.56), minor stroke (at 5 -years: $0.1 \%$ with $95 \% \mathrm{CI}:-0.8 \%$ to $1.0 \%$; $\mathrm{HR}=1.21$ with $95 \%$ CI: 0.75 to 1.96 ), and stroke in any distribution (at 5-years: $0.4 \%$ with $95 \% \mathrm{CI}:-1.5 \%$ to $2.3 \%$; $\mathrm{HR}=1.08$ with $95 \% \mathrm{CI}$ : 0.84 to 1.38 (Table 2)). Among all strokes (both major and minor), $112(43 \%)$ of the 259 post-procedural strokes were in the distribution of the artery targeted for CAS or CEA, and 147 (57\%) were outside that distribution (i.e. either contralateral or in the posterior circulation).

The homogeneity of treatment effects across studies was assessed by the addition of a trialby-treatment interaction term to the proportional hazards models. A total of 12 interaction terms were considered when the 4 outcomes (primary outcome, major stroke, minor stroke, and all stroke outcome) were considered for 3 periods (peri + post-procedural periods, periprocedural, post-procedurals). Of these 12 interactions, 1 was just marginally significant ( $\mathrm{p}$ $=0.040$ ) for the overall period, which was considered likely a spurious finding arising from multiple testing.

The results of the subgroup analysis are shown in Figure 3. The analysis of the entire followup period (all stroke in both peri-procedural and post-procedural) confirmed the previously reported lower risk of treatment by CEA compared to CAS in older patients, with similar risks in younger patients ( $p_{\text {interaction }}=0.003$ ). With a significant interaction with treatment, smoking ( $\mathrm{p}_{\text {interaction }}=0.022$ ) and the presence of contralateral severe stenosis ( $p_{\text {interaction }}=$ $0.040)$ also were documented as effect modifiers. There was no evidence of a treatment difference for smokers ( $\mathrm{HR}=0.93 ; 95 \% \mathrm{CI}: 0.61-1.41)$, while among non-smokers the risk 
was higher for treatment with CAS (HR $=1.61 ; 95 \% \mathrm{CI}: 1.30-1.99)$. Likewise, there was no evidence of a treatment effect for patients with a severe contralateral stenosis $(\mathrm{HR}=1.01$; $95 \%$ CI: $0.65-1.58$ ), while among those without a contralateral stenosis the risk was higher for treatment with CAS (HR $=1.69 ; 95 \% \mathrm{CI}: 1.35-2.13)$. During the post-procedural period, the CAS-to-CEA treatment differences were not significant within any stratum defined by any covariate, and there was no evidence of treatment effect modification (or interaction with treatment) by any covariate ( $p_{\text {interaction }} \geq 0.134$ )

Results of the per-protocol (PP) analysis were generally similar to those of the ITT analysis. Using the significance of associations as criteria, there were no differences between the ITT and PP analyses that would affect interpretation of the primary outcome, minor stroke, or stroke in any distribution. However, for major stroke, the per-protocol analysis showed a significant treatment difference both for all events $(\mathrm{HR}=1.41 ; 95 \% \mathrm{CI}: 1.02-1.94)$ and during the peri-procedural period ( $\mathrm{HR}=1.63 ; 95 \% \mathrm{CI}: 1.10-2.43)$; while in contrast the ITT analysis was not significant for either all events (HR $=1.23$; 95\% CI: $0.91-1.66)$ or for the peri-procedural period ( $\mathrm{HR}=1.39 ; 95 \% \mathrm{CI}: 0.98-1.97)$.

\section{Discussion}

This pooled analysis shows that the long-term (i.e., post-procedural) durability of CAS and CEA are remarkably similar with the annual rate of ipsilateral stroke per person year at $0.60 \%$ for CEA and $0.64 \%$ for CAS. Hence, patients remaining event-free during the periprocedural procedural period are similarly served by the CAS and CEA interventions. Nonetheless, the higher early risks following CAS are such that the primary outcome of any stroke or death out to 120 days and ipsilateral stroke thereafter favours CEA, even out to 10 years (HR=1.45; 95\% CI, 1.20 to 1.75$)$.

These results suggest the importance of on-going improvements in the peri-procedural safety of CAS, (9) including changes in CAS technology and stenting techniques and the careful selection of appropriate patients for the procedure. For example, we have previously reported that the majority of excess risk among those assigned to CAS is at older ages (10). As such, preferentially employing CAS in younger patients (i.e. age $<65$ years) could improve periprocedural safety.

The rates of long-term post procedural events reported here are low compared to prior trials for stroke preventions. If the estimated risks from Kaplan-Meier curves from the NASCET study are annualized, the post-procedural annual risk for any stroke was $4.5 \%$.(11) The comparable risk in the 4 trials reported here is $1.4 \%$ for CEA and $1.5 \%$ for CAS. Comparable data are not available for the symptomatic patients reported in the European Carotid Surgery Trial (ECST).

We do not suggest that the low long-term stroke rates herein result solely from revascularization with CEA or CEA. Risk factor control likely plays a more important role. (12). In the Asymptomatic Carotid Surgery Trial (ACST),(13) those on lipid lowering drugs at baseline had an annual rate of long-term stroke after the periprocedural period of $0.6 \%$ compared with $1.5 \%$ for those not on lipid lowering drugs. Only $9 \%$ of the patients were on 
lipid lowering drugs the first year of enrolment in ACST in 1993, and 81\% were on antihypertensive drugs. By the end of enrolment in 2003, $81 \%$ were on lipid lowering drugs, and $88 \%$ were on antihypertensive drugs.

The subgroup analysis in our pooled analysis of the entire follow-up period (all stroke in both peri-procedural and post-procedural) confirmed the previously reported lower risk for stroke of CEA (relative to CAS) in older patients (14), and also identified both smoking and the presence of contralateral stenosis as treatment effect modifiers (i.e., having an interaction with treatment). The apparent differential effect between strata defined by smoking is likely because of the confounding of age with smoking, where the average age of smokers tends to be much lower than that of non-smokers. The effect modification by the presence of contralateral stenosis requires additional investigation.

As there were only 112 post-procedural events, the subgroup analysis of treatment differences during this period should be interpreted with caution. However, the analysis presented in Figure 3 failed to detect a significant treatment difference in the post-procedural period for any stratum for any covariate, and there was not significant evidence of effect modification by any covariate; hence, it appears the similar risk for CAS and CEA during the post-procedural period is consistent for these subgroups of patients.

The advantages of this pooled analysis with individual patient data include wider generalizability and improved precision. Patients, surgical, interventionist, and medical teams from multiple countries and three continents participated. Combination of the four trials provided 4754 patients for analysis, allowing stable long-term estimates of the periprocedural risks and subsequent clinical durability for CAS and CEA as well as allowing meaningful subgroup analyses possible; these results are the most precise available.

Disadvantages include variability in surgical and interventionist training and experience, differences in outcome ascertainment and adjudication, and in intensity of patient follow-up examinations and medical treatment. A limitation of any long-term post-procedural outcome analysis is that by definition the procedures had to be performed long ago, in this case more than a decade ago. Another limitation is that we limited our analyses to first strokes, hence our report does not inform on the risk of recurrent strokes. However, 112 ipsilateral firststrokes occurred during the periprocedural period; if those patients had the very high 5-year recurrence risk for any stroke noted for NASCET (4.5\%),(11) only an additional 6 recurrent strokes would have been detected.

In summary, this pooled analysis of the four major RCTs comparing CEA and CAS demonstrates that if these procedures are performed safely, most revascularised patients can anticipate freedom from stroke at 10-years following either CEA or CAS. Nonetheless, the net long-term superiority of CEA over CAS as performed in the last decade warrants the improvements in the procedural safety of CAS that are ongoing. Accordingly, while the combined peri-procedural and post-procedural outcome results continued to favour CEA, the similarity of the post-procedural rates suggest that improvements in the peri-procedural safety of CAS could provide similar outcomes of the two procedures. The mechanisms of the post-procedural strokes that occurred over the long-term remain to be established. 


\section{Acknowledgements}

MMB's Chair in Stroke Medicine is supported by the Reta Lila Weston Trust for Medical Research. In part, this work was undertaken at University College Hospital at University College London, which received a proportion of funding from the Department of Health's NIHR Biomedical Research Centres funding scheme. AH's research is funded by the Alzheimer's Society and supported by the NIHR Oxford Biomedical Research Centre. Details of the funding supporting the original conduct of the four trials included in this pooled analysis is acknowledged in the original publications from the trials. ${ }^{1-4}$

\section{References}

1. Mas JL, Chatellier G, Beyssen B, Branchereau A, Moulin T, Becquemin JP, et al. Endarterectomy versus stenting in patients with symptomatic severe carotid stenosis. N Engl J Med. 2006; 355(16): 1660-71. [PubMed: 17050890]

2. Group SC, Ringleb PA, Allenberg J, Bruckmann H, Eckstein HH, Fraedrich G, et al. 30 day results from the SPACE trial of stent-protected angioplasty versus carotid endarterectomy in symptomatic patients: a randomised non-inferiority trial. Lancet. 2006; 368(9543):1239-47. [PubMed: 17027729]

3. International Carotid Stenting Study i. Ederle J, Dobson J, Featherstone RL, Bonati LH, van der Worp HB, et al. Carotid artery stenting compared with endarterectomy in patients with symptomatic carotid stenosis (International Carotid Stenting Study): an interim analysis of a randomised controlled trial. Lancet. 2010; 375(9719):985-97. [PubMed: 20189239]

4. Brott TG, Hobson RW 2nd, Howard G, Roubin GS, Clark WM, Brooks W, et al. Stenting versus endarterectomy for treatment of carotid-artery stenosis. N Engl J Med. 2010; 363(1):11-23. [PubMed: 20505173]

5. Carotid Stenting Trialists C. Bonati LH, Dobson J, Algra A, Branchereau A, Chatellier G, et al. Short-term outcome after stenting versus endarterectomy for symptomatic carotid stenosis: a preplanned meta-analysis of individual patient data. Lancet. 2010; 376(9746):1062-73. [PubMed: 20832852]

6. Kontis V, Bennett JE, Mathers CD, Li G, Foreman K, Ezzati M. Future life expectancy in 35 industrialised countries: projections with a Bayesian model ensemble. Lancet. 2017; 389(10076): 1323-35. [PubMed: 28236464]

7. Naylor AR, Rothwell PM, Bell PR. Overview of the principal results and secondary analyses from the European and North American randomised trials of endarterectomy for symptomatic carotid stenosis. Eur J Vasc Endovasc Surg. 2003; 26(2):115-29. [PubMed: 12917824]

8. Mas JL, Trinquart L, Leys D, Albucher JF, Rousseau H, Viguier A, et al. Endarterectomy Versus Angioplasty in Patients with Symptomatic Severe Carotid Stenosis (EVA-3S) trial: results up to 4 years from a randomised, multicentre trial. Lancet Neurol. 2008; 7(10):885-92. [PubMed: 18774745]

9. de Borst GJ, Naylor AR. In the End, It All Comes Down to the Beginning! European journal of vascular and endovascular surgery : the official journal of the European Society for Vascular Surgery. 2015; 50(3):271-2.

10. Howard G, Roubin GS, Jansen O, Hendrikse J, Halliday A, Fraedrich G, et al. Association between age and risk of stroke or death from carotid endarterectomy and carotid stenting: a meta-analysis of pooled patient data from four randomised trials. Lancet. 2016; 387(10025):1305-11. [PubMed: 26880122]

11. Barnett HJ, Taylor DW, Eliasziw M, Fox AJ, Ferguson GG, Haynes RB, et al. Benefit of carotid endarterectomy in patients with symptomatic moderate or severe stenosis. North American Symptomatic Carotid Endarterectomy Trial Collaborators. N Engl J Med. 1998; 339(20):1415-25. [PubMed: 9811916]

12. Vangen-Lonne AM, Wilsgaard T, Johnsen SH, Lochen ML, Njolstad I, Mathiesen EB. Declining Incidence of Ischemic Stroke: What Is the Impact of Changing Risk Factors? The Tromso Study 1995 to 2012. Stroke. 2017; 48(3):544-50. [PubMed: 28188260] 
13. Halliday A, Harrison M, Hayter E, Kong X, Mansfield A, Marro J, et al. 10-year stroke prevention after successful carotid endarterectomy for asymptomatic stenosis (ACST-1): a multicentre randomised trial. Lancet. 2010; 376(9746):1074-84. [PubMed: 20870099]

14. Howard G, Roubin GS, Jansen O, Hendrikse J, Halliday A, Fraedrich G, et al. Association between age and risk of stroke or death from carotid endarterectomy and carotid stenting: a meta-analysis of pooled patient data from four randomised trials. Lancet. 2016; 387(10025):1305-11. [PubMed: 26880122] 


\section{Research in context}

\section{Evidence before this study}

Over the last two decades four large randomised controlled trials (RCT) compared carotid stenting (CAS) to carotid endarterectomy (CEA) for prevention of stroke in symptomatic patients with moderate to severe carotid stenosis, the Endarterectomy versus Angioplasty in Patients with Symptomatic Severe Carotid Stenosis (EVA-3S) trial $(\mathrm{n}=527)$, the StentSupported Percutaneous Angioplasty of the Carotid Artery versus Endarterectomy (SPACE) trial $(\mathrm{n}=1200)$, The International Carotid Stenting Study (ICSS, $\mathrm{n}=1713$ ), and The Carotid Revascularization Endarterectomy vs. Stenting Trial (CREST, n=1321 symptomatic patients). We did not perform a new systematic literature search as part of this report; but since 2000, the only other completed RCT including more than 300 patients comparing CAS to CEA in recently symptomatic patients was the Stenting and Angioplasty with Protection in Patients at High Risk for Endarterectomy (SAPPHIRE) Trial $(\mathrm{n}=334)$; this study was not included in our analysis because it was performed in a different type of patient population (patients deemed at high risk for CEA, and only 96 were symptomatic).

The Carotid Stenosis Trialists' Collaboration (CSTC) previously reported short-term outcomes from pooled data from 3433 patients from the three largest European-based trials, EVA-3S, SPACE, and ICSS. The risk of stroke or death within 120 days of the procedure was $8.9 \%$ for CAS and 5.8\% for CEA (risk difference 3.2\%; 95\% CI 1.4$4.9 \%)$.

\section{Added value of this study}

In this study, the CSTC-pooled patient-level data were expanded to include data from the US-Canada trial, CREST, increasing the sample cohort to 4754 patients. The previously reported treatment difference at 120 days after randomisation is numerically unchanged by the addition of CREST. Subsequent to the 120-day peri-procedural period, the ipsilateral stroke rates were similar (approximately $0.6 \%$ per person year) for patients treated with CAS and CEA for symptomatic carotid stenosis. The rates of ipsilateral stroke are lower than the annual rates of stroke outside the distribution of the target artery, and are also lower than the post-procedural rates reported for symptomatic and asymptomatic patients in earlier randomised trials. However, the combined peri- and post-procedural risks favoured CEA.

\section{Implications of all the available evidence}

This pooled analysis provides evidence to show that for both CEA and CAS, if performed safely, most revascularised patients can anticipate freedom from stroke up to 10-years following either CEA or CAS. Nonetheless, the net long-term superiority of CEA over CAS as performed at the time of the four trials warrants the on-going efforts to improve the safety of CAS. Improvements in the peri-procedural safety of CAS could provide similar outcomes of the two procedures in both the short and long-term. 


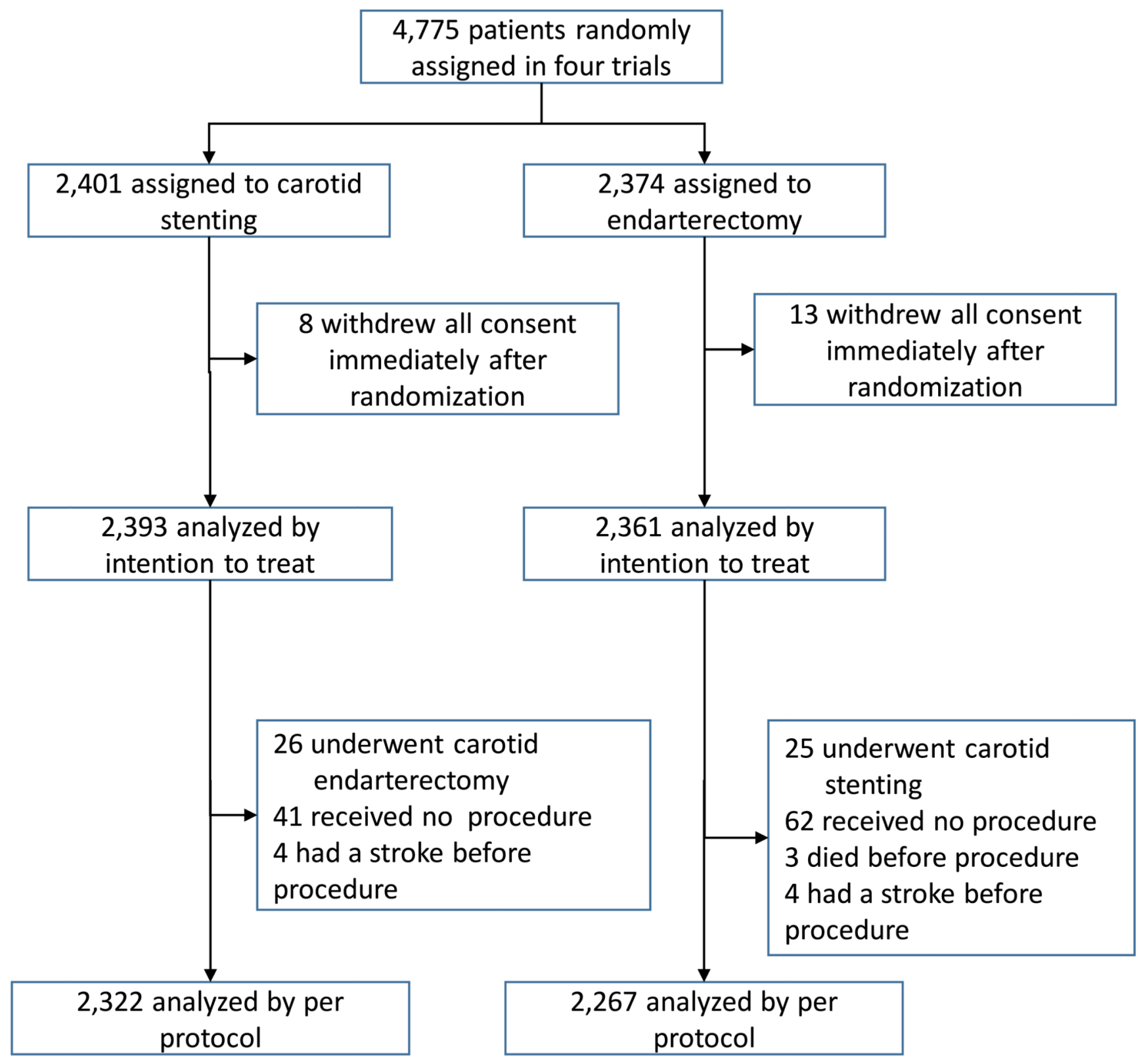

Figure 1.

Consort diagram 

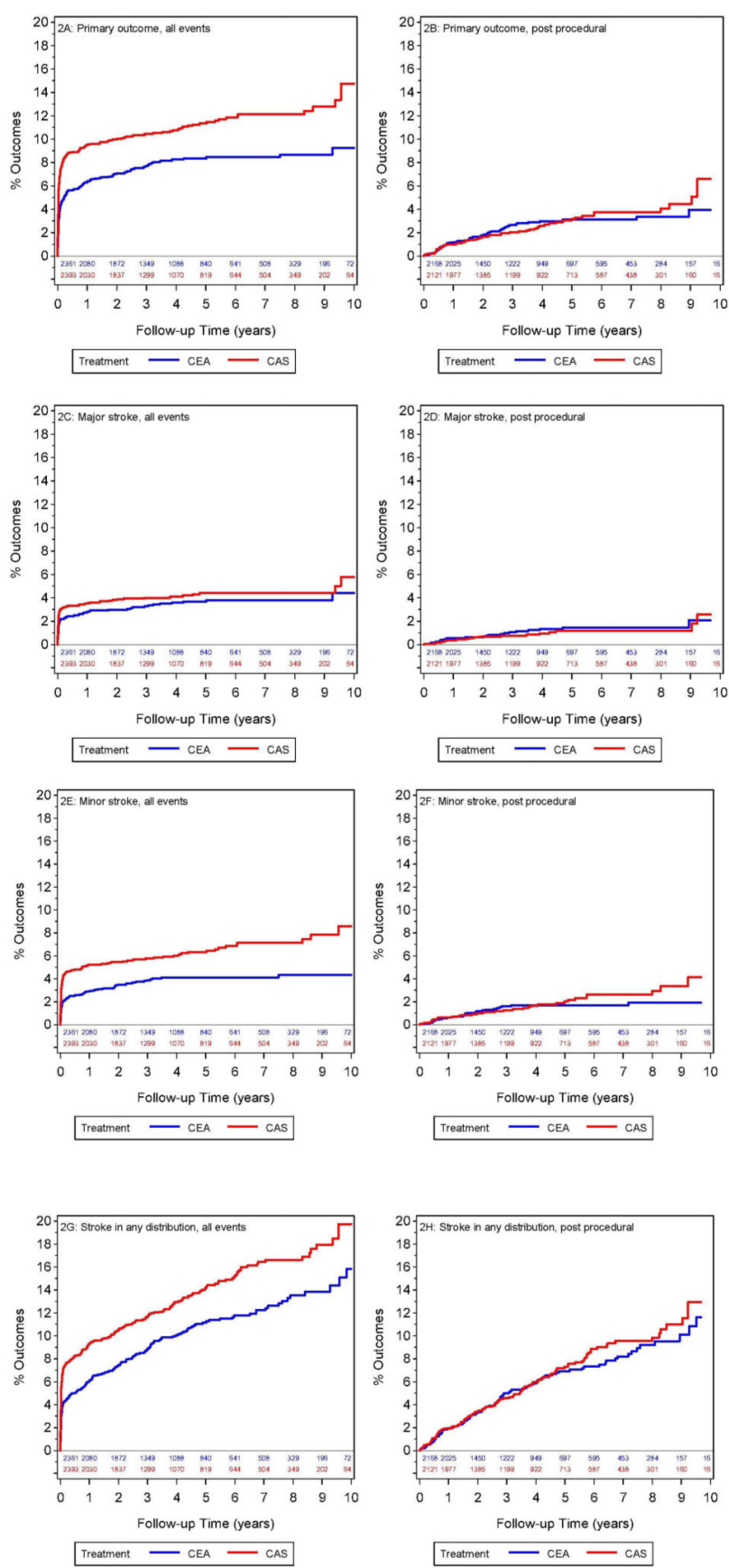

Figure 2.

A-H: Kaplan-Meier estimates of event rates for the primary outcome (Figures $2 \mathrm{~A}$ and $2 \mathrm{~B}$ ); and secondary outcomes major stroke (Figures 2C and 2D), minor stroke (Figures 2E and $2 \mathrm{~F}$ ) and all stroke (Figures $2 \mathrm{G}$ and $2 \mathrm{H}$ ). For each outcome, the event rate estimates are provided for all outcomes (including both peri-procedural and post-procedural events; Figures 2A, 2C, 2E and 2G) and for post-procedural events (i.e., post-120-day) only (Figures $2 \mathrm{~B}, 2 \mathrm{D}, 2 \mathrm{~F}$ and $2 \mathrm{H})$. 

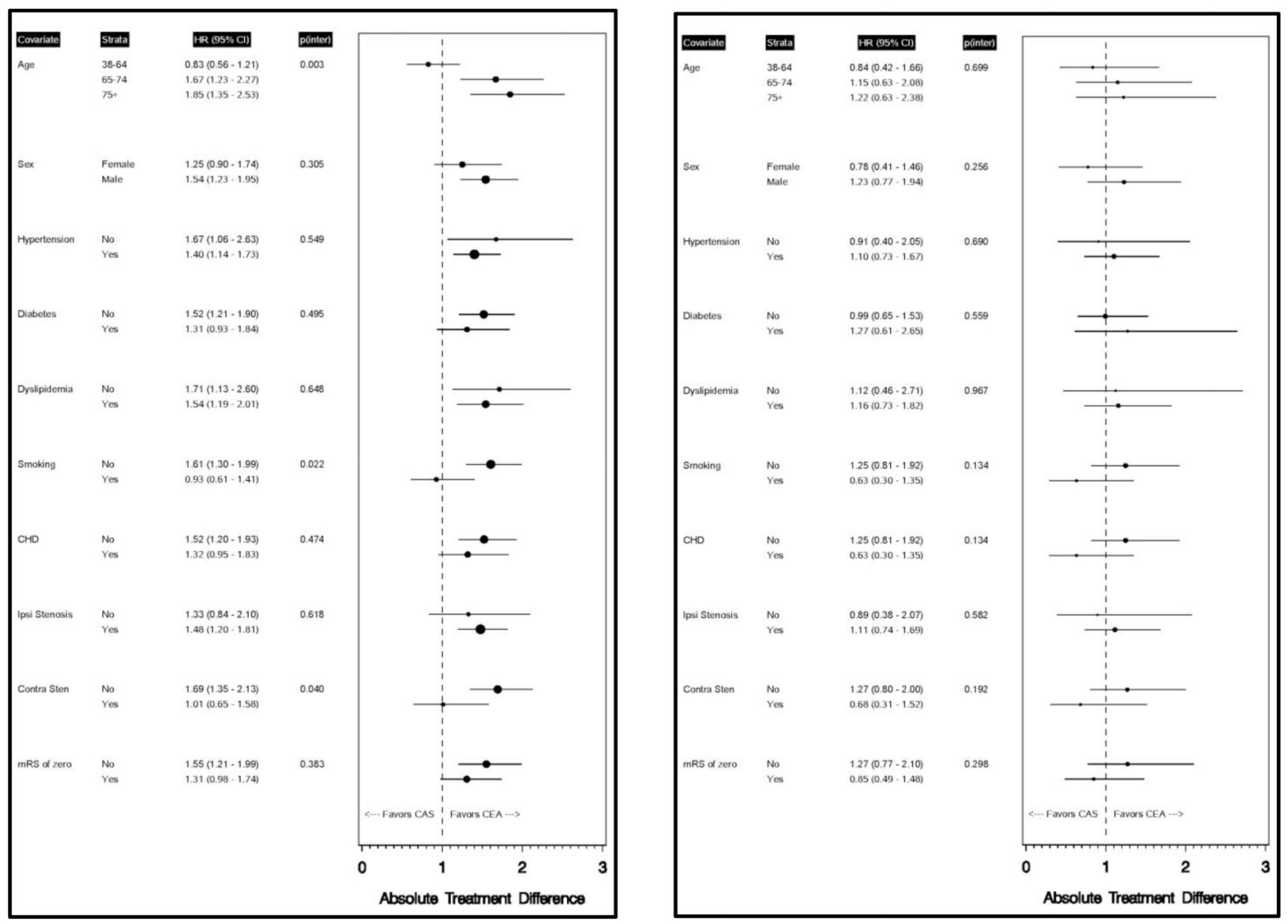

Figure 3.

Forest plot of treatment effects quantified as the CAS-to-CEA hazard ratio (with $95 \%$ confidence bounds) from proportional hazards analysis within strata defined by covariates. The figure on the left shows treatment effects for the entire follow-up period (both periprocedural and post-procedural), while the figure on the right is for post-procedural only. The size of the circle showing the treatment effect is proportional to the inverse of the standard error of the estimated difference. The p-value assessing potential effect modification was estimated by the addition of an interaction term to the proportional hazards model. 
Table 1

Description of the study population by treatment assignment and by contributing study.

\begin{tabular}{|c|c|c|c|c|c|c|c|}
\hline & \multicolumn{2}{|c|}{ Overall } & \multicolumn{4}{|c|}{ Source Trial } \\
\hline & & CEA & CAS & EVA-3S & SPACE & ICSS & CREST \\
\hline \multicolumn{2}{|l|}{ Number of Patients } & 2361 & 2393 & 527 & 1196 & 1710 & 1321 \\
\hline \multicolumn{2}{|l|}{ Age (years) (median / (p25 p75)) } & $\begin{array}{c}70 \\
(63-77)\end{array}$ & $\begin{array}{c}70 \\
(63-76)\end{array}$ & $\begin{array}{c}72 \\
(64-78)\end{array}$ & $\begin{array}{c}68 \\
(62-75)\end{array}$ & $\begin{array}{c}71 \\
(64-77)\end{array}$ & $\begin{array}{c}70 \\
(62-76)\end{array}$ \\
\hline \multicolumn{2}{|l|}{ Female $(\mathrm{k} / \mathrm{n}(\%))$} & $\begin{array}{c}702 / 2361 \\
(30)\end{array}$ & $\begin{array}{c}735 / 2393 \\
(31)\end{array}$ & $\begin{array}{c}130 / 527 \\
(25)\end{array}$ & $\begin{array}{c}338 / 1196 \\
(28)\end{array}$ & $\begin{array}{c}503 / 1710 \\
(29)\end{array}$ & $\begin{array}{c}446 / 1321 \\
(35)\end{array}$ \\
\hline \multicolumn{2}{|l|}{ Hypertension (k/n (\%)) } & $\begin{array}{c}1782 / 2350 \\
(76)\end{array}$ & $\begin{array}{c}1792 / 2381 \\
(75)\end{array}$ & $\begin{array}{c}383 / 527 \\
(73)\end{array}$ & $\begin{array}{c}904 / 1196 \\
(76)\end{array}$ & $\begin{array}{c}1183 / 1694 \\
(70)\end{array}$ & $\begin{array}{c}1104 / 1314 \\
(84)\end{array}$ \\
\hline \multicolumn{2}{|l|}{ Diabetes $(\mathrm{k} / \mathrm{n}(\%))$} & $\begin{array}{c}602 / 2356 \\
(26)\end{array}$ & $\begin{array}{l}591 / 2390 \\
(25)\end{array}$ & $\begin{array}{c}126 / 527 \\
(24)\end{array}$ & $\begin{array}{c}326 / 1196 \\
(27)\end{array}$ & $\begin{array}{c}372 / 1710 \\
(22)\end{array}$ & $\begin{array}{c}369 / 1313 \\
(28)\end{array}$ \\
\hline \multicolumn{2}{|l|}{ Dyslipidaemia (k/n (\%)) } & $\begin{array}{c}1231 / 1757 \\
(70)\end{array}$ & $\begin{array}{c}1186 / 1771 \\
(67)\end{array}$ & $\begin{array}{c}300 / 527 \\
(57)\end{array}$ & $\dagger$ & $\begin{array}{c}1085 / 1694 \\
(64)\end{array}$ & $\begin{array}{c}1032 / 1307 \\
(79)\end{array}$ \\
\hline \multicolumn{2}{|l|}{ Current Smoking (k/n (\%)) } & $\begin{array}{c}613 / 2340 \\
(26)\end{array}$ & $\begin{array}{c}606 / 2373 \\
(26)\end{array}$ & $\begin{array}{c}126 / 527 \\
(24)\end{array}$ & $\begin{array}{c}325 / 1196 \\
(27)\end{array}$ & $\begin{array}{c}403 / 1694 \\
(24)\end{array}$ & $\begin{array}{c}365 / 1296 \\
(28)\end{array}$ \\
\hline \multicolumn{2}{|c|}{ Previous Ischaemic Heart Disease (k/n (\%)) } & $\begin{array}{c}656 / 2303 \\
(28)\end{array}$ & $\begin{array}{c}637 / 2338 \\
(27)\end{array}$ & $\begin{array}{c}93 / 527 \\
(18)\end{array}$ & $\begin{array}{c}269 / 1196 \\
(22)\end{array}$ & $\begin{array}{c}467 / 1694 \\
(28)\end{array}$ & $\begin{array}{c}464 / 1224 \\
(38)\end{array}$ \\
\hline \multicolumn{2}{|c|}{ Severe ipsilateral stenosis (k/n (\%)) } & $\begin{array}{c}1896 / 2361 \\
(80)\end{array}$ & $\begin{array}{c}1939 / 2393 \\
(81)\end{array}$ & $\begin{array}{c}491 / 527 \\
(93)\end{array}$ & $\begin{array}{c}741 / 1196 \\
(62)\end{array}$ & $\begin{array}{c}1542 / 1710 \\
(90)\end{array}$ & $\begin{array}{c}1061 / 1321 \\
(80)\end{array}$ \\
\hline \multicolumn{2}{|c|}{ Severe contralateral stenosis or occlusion $(\mathrm{k} / \mathrm{n}(\%))$} & $\begin{array}{c}314 / 2115 \\
(15)\end{array}$ & $\begin{array}{c}312 / 2139 \\
(15)\end{array}$ & $\begin{array}{c}69 / 527 \\
(13)\end{array}$ & $\begin{array}{c}100 / 927 \\
(11)\end{array}$ & $\begin{array}{c}301 / 1697 \\
(18)\end{array}$ & $\begin{array}{c}156 / 1103 \\
(14)\end{array}$ \\
\hline \multicolumn{2}{|l|}{ Rankin $0(\mathrm{k} / \mathrm{n}(\%))$} & $\begin{array}{c}1172 / 2335 \\
(50)\end{array}$ & $\begin{array}{c}1200 / 2370 \\
(51)\end{array}$ & $\begin{array}{c}288 / 527 \\
(55)\end{array}$ & $\begin{array}{c}635 / 1196 \\
(53)\end{array}$ & $\begin{array}{c}675 / 1680 \\
(40)\end{array}$ & $\begin{array}{c}774 / 1302 \\
(59)\end{array}$ \\
\hline \multirow[t]{3}{*}{ Length of Follow Up (years) } & $\mathrm{N}$ & 2361 & 2393 & 527 & 1196 & 1710 & 1321 \\
\hline & Mean \pm SD & $4.2 \pm 2.9$ & $4.0 \pm 3.0$ & $6.2 \pm 3.2$ & $1.7 \pm 0.7$ & $4.0 \pm 2.1$ & $5.6 \pm 3.4$ \\
\hline & Median (IQR) & $\begin{array}{c}3.6 \\
(2.0-6.4)\end{array}$ & $\begin{array}{c}3.4 \\
(2.0-6.2)\end{array}$ & $\begin{array}{c}6.9 \\
(3.8-8.6)\end{array}$ & $\begin{array}{c}2.0 \\
(2.0-2.0)\end{array}$ & $\begin{array}{c}4.1 \\
(3.0-5.2)\end{array}$ & $\begin{array}{c}6.2 \\
(2.7-8.6)\end{array}$ \\
\hline
\end{tabular}

Dyslipidaemia data was not available in the SPACE trial. 


\begin{tabular}{|c|c|c|c|c|c|c|c|c|c|c|}
\hline 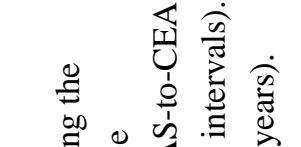 & & 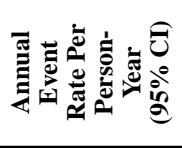 & 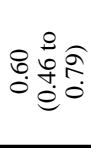 & to & กั & ปุ่ & 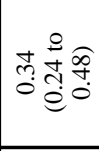 & F: & $\stackrel{\infty}{\rightarrow} \stackrel{0}{0}$ & 总 \\
\hline 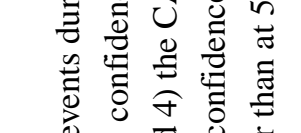 & 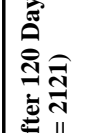 & 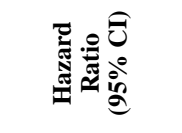 & \multicolumn{2}{|c|}{ 我舀 } & \multicolumn{2}{|c|}{ 等 } & \multicolumn{2}{|c|}{ ㄲํำ } & \multicolumn{2}{|c|}{ 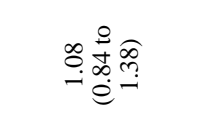 } \\
\hline 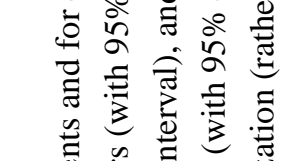 & 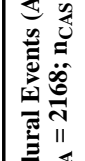 & 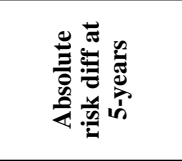 & \multicolumn{2}{|c|}{ 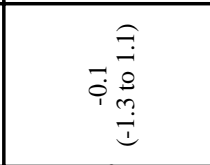 } & \multicolumn{2}{|c|}{ 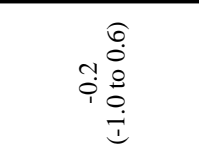 } & \multicolumn{2}{|c|}{ 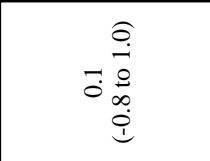 } & \multicolumn{2}{|c|}{ 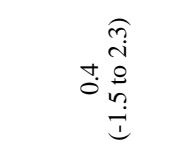 } \\
\hline 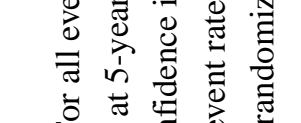 & 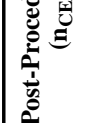 & 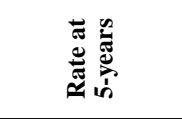 & लंलें & i $\frac{0}{\mathrm{i}} \hat{\sigma}$ & m. & ㄴํㅇ & ־ & 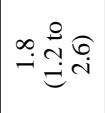 & ช่ำ & 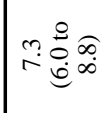 \\
\hline 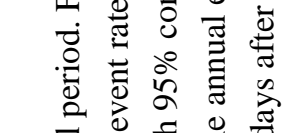 & & \#产 & in & in & 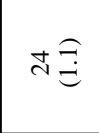 & तิ & $\bar{m} \stackrel{f}{=}$ & 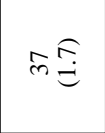 & 赵 & 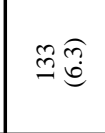 \\
\hline 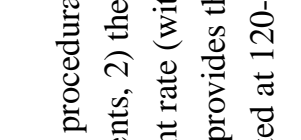 & 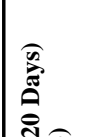 & 乎 & \multicolumn{2}{|c|}{ 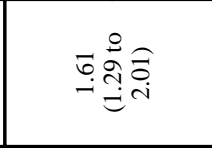 } & \multicolumn{2}{|c|}{ mेळấ } & \multicolumn{2}{|c|}{ 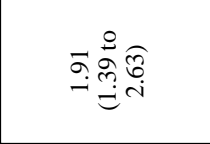 } & \multicolumn{2}{|c|}{ 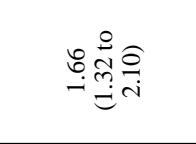 } \\
\hline 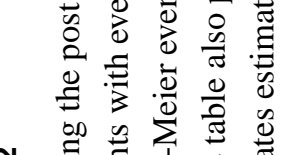 & 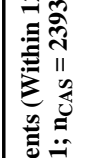 & 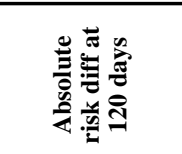 & \multicolumn{2}{|c|}{ 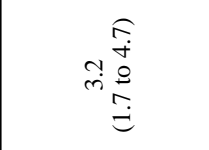 } & \multicolumn{2}{|c|}{ 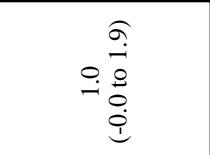 } & \multicolumn{2}{|c|}{ 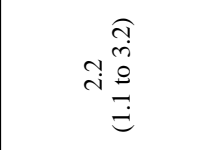 } & \multicolumn{2}{|c|}{ 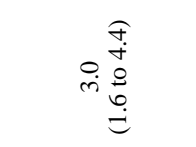 } \\
\hline 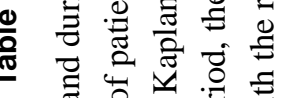 & 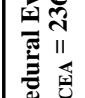 & 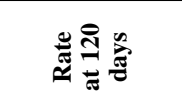 & 路年 & م $\stackrel{8}{0} \sigma$ & 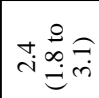 & mid & 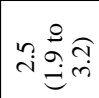 & 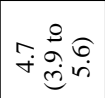 & 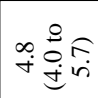 & 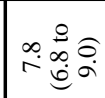 \\
\hline 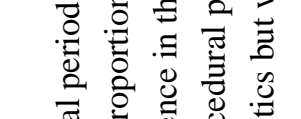 & $\mid$ & $\#$ 童高 & ปิ ปิ & 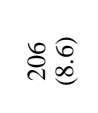 & in $\widehat{\tilde{d}}$ & ஜ) & in $\underset{\mathrm{d}}{\mathrm{f}}$ & 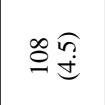 & 壾 & $\stackrel{\infty}{\stackrel{\overbrace{}}{\check{c}}}$ \\
\hline 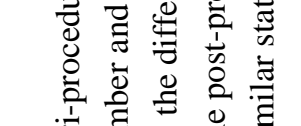 & & 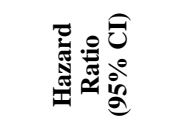 & \multicolumn{2}{|c|}{ 等 } & \multicolumn{2}{|c|}{ तิ } & \multicolumn{2}{|c|}{ 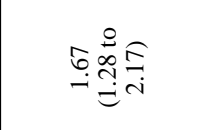 } & \multicolumn{2}{|c|}{ m̊ng } \\
\hline 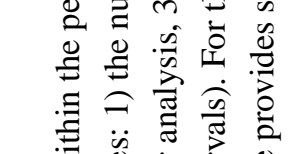 & 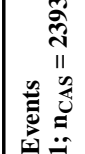 & 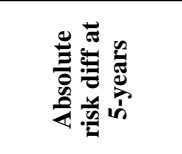 & \multicolumn{2}{|c|}{ 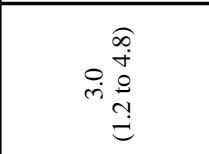 } & \multicolumn{2}{|c|}{ rin } & \multicolumn{2}{|c|}{ 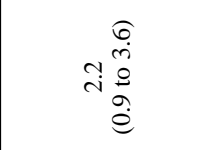 } & \multicolumn{2}{|c|}{ 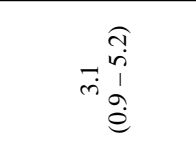 } \\
\hline 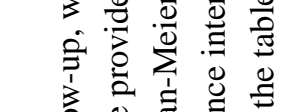 & 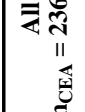 & 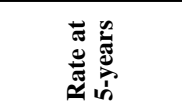 & m. & 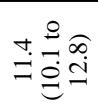 & ґே & 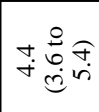 & F⿳亠丷厂犬 & ชुํำ & 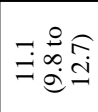 & 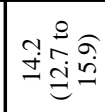 \\
\hline 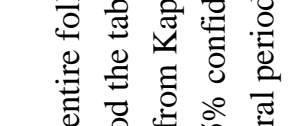 & & $\#$ 童高 & $\stackrel{ \pm \underset{\infty}{\infty}}{\stackrel{\infty}{\subseteq}}$ & 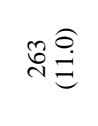 & શ̊ & ஃ。 & $\infty \underset{\infty}{\infty} \underset{\infty}{\tilde{c}}$ & 哭 & 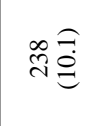 & 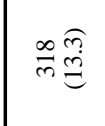 \\
\hline 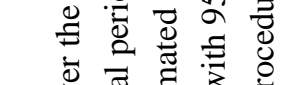 & & & 丞 & है & 昰 & है & 㺼 & ठ̀ & 岀 & है \\
\hline 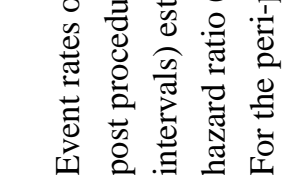 & & & 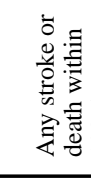 & 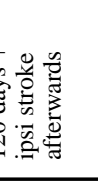 & 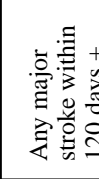 & 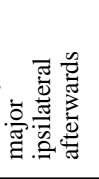 & 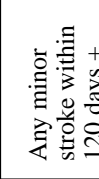 & 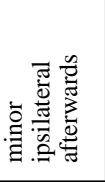 & & $=$ \\
\hline
\end{tabular}




\section{Table 3}

Event rates for primary event outcome and ipsilateral post-procedural stroke by treatment assignment (with 95\% confidence interval), and differences in treatment (with 95\% confidence interval) at 1, 3, 5, 7 and 9 years.

\begin{tabular}{|c|c|c|c|c|c|c|}
\hline \multirow{2}{*}{ Outcome } & \multirow{2}{*}{ Treatment } & \multicolumn{5}{|c|}{ Years post-randomization } \\
\hline & & $\mathbf{1}$ & 3 & 5 & 7 & 9 \\
\hline \multirow{3}{*}{$\begin{array}{l}\text { Long-term Outcome (peri + post) }(\% \text { : } \\
95 \% \text { CI })\end{array}$} & CEA & $\begin{array}{c}6.4 \\
\text { (5.4 to } 7.4)\end{array}$ & $\begin{array}{c}7.7 \\
\text { (6.7 to } 8.9)\end{array}$ & $\begin{array}{c}8.3 \\
\text { ( } 7.2 \text { to } 9.6)\end{array}$ & $\begin{array}{c}8.4 \\
\text { ( } 7.3 \text { to } 9.7)\end{array}$ & $\begin{array}{l}8.7 \\
(7.5 \text { to } 10.0)\end{array}$ \\
\hline & CAS & $\begin{array}{l}9.5 \\
\text { (8.4 to } 10.8)\end{array}$ & $\begin{array}{c}10.5 \\
(9.3 \text { to } 11.8)\end{array}$ & $\begin{array}{c}11.4 \\
(10.1 \text { to } 12.8)\end{array}$ & $\begin{array}{c}12.1 \\
(10.7 \text { to } 13.7)\end{array}$ & $\begin{array}{c}12.5 \\
(11.2 \text { to } 14.6)\end{array}$ \\
\hline & $\begin{array}{l}\text { CAS - CEA } \\
\text { Difference }\end{array}$ & $\begin{array}{c}3.1 \\
(1.6 \text { to } 4.7)\end{array}$ & $\begin{array}{c}2.8 \\
(1.1 \text { to } 4.4)\end{array}$ & $\begin{array}{c}3.0 \\
(1.2 \text { to } 4.8)\end{array}$ & $\begin{array}{c}3.7 \\
(1.8 \text { to } 5.6)\end{array}$ & $\begin{array}{c}4.1 \\
\text { (2.0 to } 6.3)\end{array}$ \\
\hline \multirow{3}{*}{$\begin{array}{l}\text { Post-Procedure Durability (post only) } \\
(\%: 95 \% \mathrm{CI})\end{array}$} & CEA & $\begin{array}{c}1.2 \\
(0.8 \text { to } 1.7)\end{array}$ & $\begin{array}{c}2.6 \\
\text { (2.0 to } 3.5)\end{array}$ & $\begin{array}{c}3.1 \\
(2.3 \text { to } 4.1)\end{array}$ & $\begin{array}{c}3.1 \\
(2.3 \text { to } 4.1)\end{array}$ & $\begin{array}{c}3.9 \\
(2.7 \text { to } 5.8)\end{array}$ \\
\hline & CAS & $\begin{array}{c}1.0 \\
(0.6 \text { to } 1.5)\end{array}$ & $\begin{array}{c}2.0 \\
(1.5 \text { to } 2.8)\end{array}$ & $\begin{array}{c}3.2 \\
(2.3 \text { to } 4.2)\end{array}$ & $\begin{array}{c}3.7 \\
(2.8 \text { to } 5.0)\end{array}$ & $\begin{array}{c}4.5 \\
\text { (3.2 to } 6.2)\end{array}$ \\
\hline & $\begin{array}{l}\text { CAS - CEA } \\
\text { Difference }\end{array}$ & $\begin{array}{c}-0.2 \\
(-0.8 \text { to } 0.4)\end{array}$ & $\begin{array}{l}-0.6 \\
(-1.6 \text { to } 0.4)\end{array}$ & $\begin{array}{c}0.0 \\
(-1.2 \text { to } 1.3)\end{array}$ & $\begin{array}{c}0.6 \\
(-0.7 \text { to } 2.0)\end{array}$ & $\begin{array}{c}0.5 \\
(-1.6 \text { to } 2.7)\end{array}$ \\
\hline
\end{tabular}

